\title{
Deepening Teaching Reform and Promoting Higher Vocational Education
}

\author{
Caihong Zhu ${ }^{1, a^{*}}$ and Hongtao Zhang ${ }^{1, b}$ \\ ${ }^{1}$ Suzhou Vocational University, Suzhou, China \\ azhuzhang_2000@163.com, bch@jssvc.edu.cn
} Keywords: Teaching reform; High vocational education; School-enterprise cooperation;
Educational philosophy; Talent training

\begin{abstract}
The fundamental task of colleges and universities is to cultivate talents. Teaching work is always the central work of the school. We must continue to deepen the teaching reform, establish a sense of quality, teaching innovation awareness and teaching characteristics of consciousness, in order to cultivate high-quality to adapt to market and social needs of the compound skills.
\end{abstract}

\section{Introduction}

Trend of economic globalization makes the skilled personnel training in our country is in the grip of an unprecedented sense of urgency, the rapid development of science and technology puts forward new requirements of laborers' comprehensive quality, industry structure and employment structure changes make labor cross-industry liquidity increases, and more and more high to the requirement of the training. The professional setting of the original vocational education has formed the structure dislocation with the employment posture to a certain extent, the curriculum establishment and the teaching content obviously lag behind the skill development demand of the professional post. The international competition is becoming more and more intense, which requires the vocational education to adjust correspondingly to the development of the society on the level and quality standard of the talented person and the training goal $[1,2]$.

The fundamental task of colleges and universities is to cultivate talents, teaching work has always been the center of the school work. We must continue to deepen the teaching reform, establish a sense of quality, teaching innovation awareness and teaching characteristics of consciousness, in order to cultivate high-quality to adapt to market and social needs of the compound skills [3]. To do a good job of teaching reform, we should pay attention to the following aspects.

\section{Ensuring the Center of the Teaching}

The nature of education is to cultivate people's a kind of social activity, higher education is to cultivate various types of high-level specialized personnel of social activities. High education has three functions: cultivating talents, developing science and social services. The training of talent is the most basic, the most important, and plays a qualitative and regulatory functions. Leaving the training of personnel, it will not be into higher education and higher education. Personnel training is mainly achieved through the activities of education and teaching activities. Therefore, the teaching work is naturally in the center of the work of the school, which is determined by the law of education itself [4].

\section{Setting up an Advanced Educational Philosophy}

With the rapid development of science and technology, the intensification of social competition and the arrival of economic globalization, vocational education must establish a new educational idea based on "learning to know, learning to do, learn to survive and learn to cooperate", and mainly set up the lifelong education and the education concept of sustainable development; and establish a capacity-based, employment-oriented education philosophy; foster students awareness of cooperation and cooperation in the educational concept. 


\section{Strengthening the School Education, Led by Moral Awareness}

Strengthening and improving moral education work, is to improve the ideological and moral qualities of educates, and is the important measure to realize the goal of cultivating goals of vocational school. Vocational school moral education has its particularity. It is necessary to combine the theory education with social practice, combine ideological education with strict management, pay attention to the progress of students 'thought and guide students' study and life, and combine the methods of the flexible and diverse educational teaching. School education is led by moral education. All teachers should continue to learn moral knowledge of moral education, to establish the idea of a student-centered thinking and set up the consciousness of "everyone is a moral educator" $[5,6]$.

\section{Paying Attention to the Construction of Double-qualified Teachers}

Chinese vocational education teachers in our country with ability as the standard of professional teaching modes are basically a discipline-based teacher, and are difficult to adapt to the education ideology, teaching concepts, and knowledge and skills structure, teaching methods. To fundamentally change the status of vocational education teachers in our city to enhance the quality of vocational education teachers, it should be to develop "double-type", a multi-skilled teachers focusing on strengthening the professional teaching skills and training; to encourage and urge teachers to study the direction, methods, content and form of teaching; to strengthen the backbone of the discipline. Teachers play a dominant role in advancing teaching reform [7]. Teachers are the motive force to promote the development of teaching reform. The role of part-time teachers is an important part of school teaching management. Teachers' subjective initiative is the key to the success of teaching reform. The school should take effective measures to support the policy, standardize the system, promote the teachers to change their concepts, and actively participate in, and effectively stimulate the enthusiasm of teachers to practice teaching reform. The formation of practical ability in the teaching of the course training mode, can make students adapt to the work side, while learning, while the accumulation of side to improve the learning needs of the characteristics, so that both teaching and learning fully embody the characteristics of lifelong learning.

\section{Building a Scientific Curriculum Structure}

At present, the curriculum system of vocational education emphasizes on the subject knowledge system, ignoring their professional skills requirements; and its knowledge obsolete, slow update, not reflecting the new level of technological development; and its content is deep, difficult, does not meet the cognitive level of the vocational school students. The content of teaching does not match the ability required by professional, industry job positions with the difference of theory and application. Without reform of teaching content, students refuse to learn, weariness is inevitable. Therefore, first of all, the curriculum system should be built around the training objectives. It is necessary to gradually shift from a single vocational curriculum to a comprehensive vocational curriculum, and from a subjective vocational curriculum to a competency-based vocational curriculum. Second, in order to adapt to the curriculum need, the school-based teaching materials need to strengthen the construction $[8,9]$.

\section{Implementing Teaching Plan According to Students}

The difference in cultural knowledge and ability level of vocational school students is very big. In order to better face to all students, public basic course can be layered teaching, target-oriented according to their aptitude. To cultivate the ability as the goal, the pilot implementation of the teaching method reform can take "three point one line" teaching method. "Three points" includes classroom, practice workshops and internship enterprises. In traditional vocational education, the theoretical teaching and practice are separated, unified organization of professional practice tend to be in after the professional theory. The "dual system" teaching practice "three points and one line", and Educator Tao Xingzhi [10] advocated "the unity of" teaching and learning have in common. In the classroom teaching to solve the 
problem of "should know", including generous basic knowledge, expertise and knowledge for training preparation. Its purpose is to tell the students why and why to do so is correct. In the workshop solve the "should", that is, the skills to master the problem, including the actual skills, knowledge, practical ability to solve problems and the ability to collaborate with each other. The main purpose is to enable students to understand how to do, and solve the problem in the practice of skilled enterprises. As a "line" is the organic combination of the three "points", mutual penetration.

\section{Playing the Role of University-enterprise Cooperation and Industry Participation}

Under the condition of market economy, the enterprises have been reorganized through their own restructuring and mutual reorganization. The layout and link of productivity have been reorganized, and the resource allocation has been further optimized. In the process of optimizing development, enterprises not only pay attention to their own development environment, but also began to pay attention to the optimization of human resources development work. In order to choose the excellent employees to enter the factory, in the selection of the general migrant workers, the short-term professional training of migrant workers and qualified professional graduates, enterprises tend to bias the latter. In the latter's choice, both focus on skills and pay more attention to the selection of the basic quality. Therefore, vocational schools especially need enterprise industry experts, common design training scheme in the development of training objectives, curriculum development, as well as student knowledge and ability to determine the structure. In the process of teaching practice, vocational schools need to have practical experience of professionals and craftsmen as part-time teachers in the training of skills, while the occupation of professional norms and corporate culture; vocational school teachers also need regular business to part-time to grow practice and to understand the latest technology to understand the actual needs of enterprises and corporate culture. Enterprises and schools organized professional examination and skill appraisal and teaching quality is not high, students' skill is good, which is evaluated by industry experts, and really put into use, mount guard them [11].

\section{Widening the Channel of the Social Training and Talents Output}

Local economic take-off requires a lot of talent, human resources rely on the output of vocational education, to achieve the national first-class high-level personnel training base and sing the grand goal of vocational brand, we are doing regular institutions of higher learning doesn't work, and that how to develop vocational education bigger, better and stronger is fundamental. Vocational school must pay attention to the social development track, take the initiative to adapt to the labor market demand, timely adjust and update the professional settings, teaching content and teaching methods, and continuously improve the quality of education. The vocational education will be "vista", radiate bright brilliance.

\section{Conclusion}

Teaching reform is a means, its real purpose is to improve the efficiency of education through teaching reform, improve the level of school teaching services, and ultimately improve student learning efficiency [12]. Under the background of promoting the development of lifelong education, how to highlight the characteristics of education in higher vocational education, so that the training model more practical, more in line with the characteristics of vocational needs, more in line with the direction of employment and more effective life-long education, is a modern education providers to seriously study, actively correspond to the courage to practice. It will have a positive role in promoting the intensity of education and teaching reform, improving the level of education and teaching and strengthening teaching quality management.

\section{Acknowledgement}

In this paper, the research was sponsored by the Brand Professional Construction Engineering Projects in Colleges and Universities of Jiangsu Province (Project No. PPZY2015A089). Meanwhile I 
would like to take this opportunity to show my sincere gratitude to Mr. Zhang Hongtao, who has given me so much useful advices on my writing, and has tried his best to improve my thesis.

\section{References}

[1] X.R. Cai, Y.F. Kong: Journal of the AE, Vol. 300 (2012) No.1, p.85.

[2] W.R. Jia: Journal of the YTE, Vol. 30 (2016) No.1, p.143.

[3] L.J. Zhu, X. Luo and F. Li: Journal of the ZQKTZYJIXY, Vol. 22 (2016) No.1, p.9.

[4] J. Li: Journal of the CPVE, Vol. 16 (2016) No.1, p.53.

[5] P. Zhou, Y. Song: Journal of the JYYZY, Vol. 16 (2016) No.14, p.59.

[6] G.M. Jia: Journal of the DDJYLLYSJ, Vol. 325 (2016) No.8, p.161.

[7] Information on http:// www.tech.net.cn/N123/2009050700023.html.

[8] Information on http://www.chsi.com.cn/jyzx/201508/20150821/1503312292.html.

[9] J.Q. Huang: Journal of the Education, Vol. 328 (2016) No.7, p.264.

[10] Information on http://www.moe.edu.cn/jyb_xwfb/moe_176/201511/t20151123_220559.html.

[11] T.T. Guo: Journal of the JYGLZ, Vol. 16 (2016) No.33, p.407.

[12] H. Hu, Z.J. Tao and B.W. Yang: Journal of the HUAS, Vol. 22 (2010) No.4, p.58. 